\title{
Exploring the Adventist Health-lifestyle: A Social Marketing Perspective
}

\author{
Innocent Sigauke, $\mathrm{PhD}^{1^{*}}$, Kenneth Swansi, $\mathrm{PhD}^{2}$ and Christinah Dlamini, $\mathrm{PhD}^{1}$ \\ ${ }^{1}$ Solusi University, Zimbabwe \\ ${ }^{2}$ Adventist International Institute of Advanced Studies, Philippines \\ *Corresponding Mail: sigaukei@solusi.ac.zw
}

\begin{abstract}
Some studies have linked the Seventh-day Adventist (SDA) church health-lifestyle with better wellbeing and longevity. However, there are suggestions that current initiatives by the SDA-church to prompt health behavior modifications have been inadequate. Current attempts seem to be largely downstream approaches without clear marketing guidelines. While social marketing has been noted to be a key success factor in behavior modification initiatives, it does not seem to have been used in promoting SDA healthlifestyle initiatives. Hence the study sought to bring in a social marketing perspective to the current initiatives being done to make the SDA health-lifestyle modifications attainable for more people. A multi-method design combining grounded theory and appreciative inquiry was used. Data was collected from SDA-public health academics and practitioners, health-lifestyle program participants as well as social marketing extant studies and models. The sources of data were 30 interviews, 20 extant studies on social marketing, 5 social marketing models and 5 forum presentations. The major finding of the study is a social marketing theory for SDA healthlifestyle modification suggesting that health-lifestyle behavior modification is driven by centers of influence that run benchmarked programs shaped by distinctively Adventist worldview, and guided via marketing design criteria. Social marketing is suggested as the missing link that makes it easier to implement healthlifestyle behavior adoption efforts.
\end{abstract}

Keywords: Social marketing, social marketing model, Seventh-day Adventist, health-lifestyle, lifestyle, grounded theory, appreciative inquiry, behavior modification

\section{Introduction}

Studies have revealed that social marketing has the potential to elicit desired changes when used as an intervention method in societal problems (Evans, 2008; Kemp \& Eagle, 2008; Longest \& Rohrer, 2005; Ludwig, Buchholz, \& Clarke, 2005; Watson, Tomar, Dodd, Logan, \& Choi, 2009). For example, a metaanalysis by Sweat, Denison, Kennedy, Tedrow and O'Reilly (2012) and another by Hung (2017) indicated a positive correlation between social marketing interventions and positive behavioral change. Additionally, the Rotary Club International used social marketing successfully for polio eradication in the Philippines in 1979 and subsequently in 125 other countries after the year 1985 (Lee \& Kotler, 2016). Accordingly, social marketing is suggested as the emerging key success factor for behavior change initiatives. Even though social marketing is a potential key success factor in successful behavioral change initiatives and is being used more and more, its use can still be extended to other areas where behavioral change is necessary.

About 20 million people die every year due to communicable diseases (NCDs) which can be reduced through behavior change (Galvez 2016). Additionally, while the Blue Zone studies have isolated the SDA health-lifestyle as being pivotal in enhancing longevity (Buettner, 2010), Galvez (2016) alludes to the defective nature of current efforts to promote health-lifestyle practices among the SDAs. He reported that SDA health promoters are frustrated by current efforts to promote the SDA health-lifestyle. The frustrations are said to be a result of poor and inaccurate presentation of the health message, an overemphasis of vegetarianism or veganism, lack of contextualization and using the health message as a test of discipleship. 
Accordingly, the problem can be understood on two main points. On one end, social marketing is a potential key success factor in behavioral change initiatives but there seems to be minimal evidence of its use in promoting SDA health lifestyle initiatives. On the other, while SDA sponsored health-lifestyle initiatives have been observed to be effective in enhancing health and longevity, health promoters of SDA health behavior were reported to be frustrated because their promotional efforts were not successful. As a result, the prevalence of non-communicable diseases is still high. Appreciative inquiry and grounded theory were thus used to draw lessons that can be useful in addressing the challenges in marketing the SDA health-lifestyle initiatives.

The goal of this study was to appreciate the best that there is in social marketing extant studies, social marketing models and SDA health-lifestyle program academics, practitioners and participants. The study also aimed to identify key factors that can be useful in constructing a social marketing theory for SDA health-lifestyle modification.

\section{Literature Review}

This section addresses the description of social marketing as a discipline. The highlighted topics include an introduction to social marketing, social marketing impact areas and the power of social marketing. Notably the review was brief and noncommittal in line with grounded theory designs (see Corbin \& Strauss 2015; Urquhart 2013).

\section{Introduction to Social Marketing}

Social marketing is a fledging discipline which has led to great success in correcting social ills ranging from infant mortality to recycling (Lee \& Kotler, 2016). But what is social marketing? Andreasen (as cited in Lee \& Kotler, 2016) presents a simple but comprehensible description which states that "Social marketing is the application of commercial marketing concepts and tools to influence the voluntary behavior of target audiences to improve their lives or the society for which they are part" (p.9). This definition describes social marketing in the context of commercial marketing. As a result, the starting point regarding the discipline focuses on how it is similar or different from commercial marketing. One of the key distinctions between social marketing and commercial marketing is the difference in goals. While commercial marketing is premised on profit and financial gain for the marketer, social marketing revolves around behavior change, which benefits the individual together with the society (Lee \& Kotler, 2016). Besides, it seems that the marketing management processes of commercial marketing are also applicable to social marketing. Such processes include-research, segmentation, targeting, positioning, branding and the marketing mix (Kotler 1999).

\section{Social Marketing Impact Areas}

Social marketing impacts five major areas of behavior: health, the environment, injury prevention, community involvement and financial behaviors (Lee \& Kotler, 2016). For example, some examples of social marketing impact areas include fruit and vegetable intake as health behaviors, while the promoting banking among individuals are financial behaviors. This study sought to address lifestyle behavioral change, which comes under the area of health in line with Lee and Kotler's (2016) classification.

\section{The Power of Social Marketing}

Commercial marketing has made an indelible mark in society because of the way it has proved to be an effective tool in influencing behavior. It has been so effective that it has been credited with adding choices available to consumers but, it's also said to be the force behind social ills such as smoking and materialism. Inadvertently, such criticism only serves as proof of the effective influence of marketing on human behavior (Andreasen, 2006; Lefebvre, 2013). Social marketing piggybacks on commercial marketing which has already proven to be effective, hence it is poised to be a potent force for social change. The study thus sought to use appreciative inquiry to tap into the marketing potency to influence health lifestyle choices as well as grounded theory to formulate a theory.

\section{Research Methodology}

The methodology of this study is outlined as follows: research design, population and sampling, and data collection procedures. The discussions attempt to provide a detailed account of how the study was done; however, such detail does not suggest that the study was conducted in a rigid, linear lockstep fashion. Rather, the process was flexible, iterative and emergent in line with a grounded theory research design.

\section{Research Design}

The study employed a multimethod research design. A multimethod design is one in which more than one method from the same design (qualitative + 
qualitative or quantitative +quantitative) are used in one study (Hunter and Brewer 2015; Schoonenboom \& Johnson 2017). Mixed methods are distinct from multimethod designs in that the former combines a qualitative method with a quantitative method while the later combines methods within the same design (Schoonenboom \& Johnson 2017). A research method should be chosen on the basis of its appropriateness in addressing the research questions and the research problem under review (Charmaz, 2014; Glaser and Strauss (1967)). As a result, this study employed the appreciative inquiry and grounded theory because these two methods addressed the appreciative theory building goal of this study. Using more than one method makes a study robust (Swartz, Amatucci, \& Coleman 2016). The appreciative framework made it possible to value the data sources for the best that they had in terms of the social marketing aspects and the SDA healthlifestyle that the study focused on. On the other hand, grounded theory made it possible to collect the data and analyze it to develop a theory to suit the purpose of the study.

\section{Population and Sampling}

The study was on SDA health-lifestyle hence SDA public health academics and practitioners as well as SDA health-lifestyle program participants provided data on the SDA health-life initiatives. The participants were purposively selected because of their positions, contribution or experience in health lifestyle issues in the SDA Church. The participants were interviewed in the Philippines. However, due to the global nature of the operations of the SDA church, they were from different parts of the globe including: Cameroon, Fiji, India, Myanmar, Nigeria, USA and Zimbabwe. They comprised 6 professors in two SDA institutions in the Philippines, 2 health lifestyle doctors and 1 administrator from one of the SDA medical centers in the Philippines, 3 medical doctors from SDA health centers in the USA who happened to be in the Philippines when the data was being collected, 5 individual SDA members in the Philippines who engaged in health promotion related activities like running a vegetarian restaurant, 1 serving health director, 1 retired former division health director and 11 SDA members from diverse stations of life who participated in the CHIP program and the TAKE CONTROL programs. TAKE CONTROL was a health behavior program run by one of the public health departments in one of the SDA academic institutions. While Glaser and
Strauss (1967) lamented the untapped potential in library resources that represent "voices begging to be heard" (p. 163), social marketing models and social marketing extant studies provided data on the social marketing aspects.

The sources of data were 30 interviews, 20 extant studies on social marketing, 5 social marketing models and 5 forum presentations. Four important questions helped in the theoretical sampling process "theoretical plausibility, direction, centrality and adequacy" (Charmaz, 2014, p. 87). As such, to begin with, SDA public health academics were considered because they were expected to possess knowledge on SDA health-lifestyle adoption best practices that they disseminate to students. Subsequently, the experiences of alumni in SDA health-lifestyle programs served to highlight the positive experiences of such programs from the point of view of the program beneficiaries. This was followed by the experiences and views of the practitioners which served to highlight the positive experiences from the point of view of those implementing the programs. Furthermore, the social marketing extant studies and social marketing models provided data on social marketing issues. Existing social marketing models served as a comparison point. As a result, theoretical relevance and adequacy was adequately addressed.

\section{Data Collection Procedures}

Data was collected through open ended face to face interviews, focus group discussions, notes from a forum and review of extant studies in response to the emergent theoretical sample. Interviews were used to collect data from SDA health directors, practitioners and academics. An interview guide adapted from Bryman and Bell (2007), Cooperrider, Whitnye, and Stavros (2008) and Zikmund, Babin and Griffin (2013), was used to ensure that all the 4Ds of appreciative inquiry were explored. The four D's are discover, dream, design and deliver.

\section{Findings and Discussion}

The purpose of the study was to develop a substantive social marketing theory on the SDA health-lifestyle change and to draw appreciative lessons on the marketing of the SDA health-lifestyle. The major finding is a social marketing theory for SDA health-lifestyle behavior modification and its components. The components of the theory thus represent the propositions and lessons on the social marketing of the SDA health-lifestyle. The overriding finding in this study is that SDA health-lifestyle 
behavior modifications can come about as a result of centers of influence that adopt social marketing design criteria.

\section{A social marketing theory for SDA health- lifestyle change (substantive theory)}

The emergent theory combines emergent themes from the three data sources used in the study. Therefore, the finding represented by the theory statement is that health-lifestyle behavior modification is driven by centers of influence that run benchmarked programs shaped by distinctively SDA worldview via social marketing design criteria such as marketing strategy, built-environment, benchmarking criteria and design procedures. The theory is illustrated by Figure 1. Each component of the theory-centers of influence; guiding philosophy; program benchmarking; strategies and actions; and social marketing design criteria are explained in the ensuing section. Data supporting these components is also highlighted.

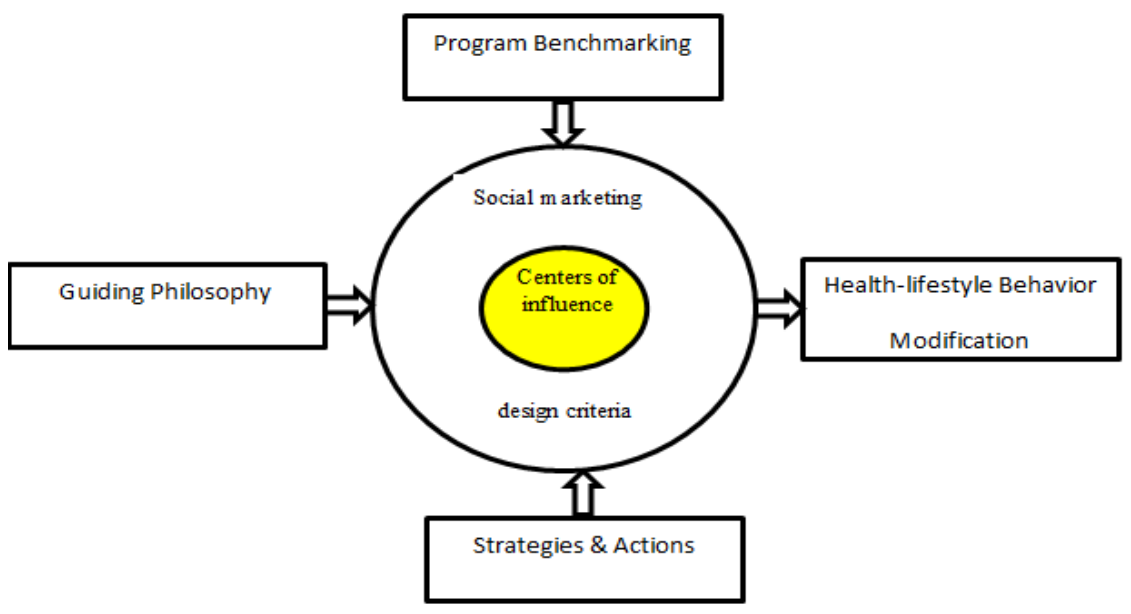

Figure 1: Emerging Social Marketing Theory for Adventist Health-lifestyle Modification

Table 1: Centre of Influence Interview Excerpts

\begin{tabular}{|c|c|c|}
\hline Case & Concept & Interview excerpt \\
\hline 7 & $\begin{array}{l}\text { Center of } \\
\text { influence }\end{array}$ & $\begin{array}{l}\text { "It's like fire, that the more you join them together, the more light you will have. . . . So, } \\
\text { when you have a program, they can help themselves, so they can be ignited and also catch } \\
\text { the influence. What you are saying now is called a center of influence. The church should } \\
\text { have its own health programming depending on need." }\end{array}$ \\
\hline 18 & Influence & $\begin{array}{l}\text { "It's not just for our church. It's not just for Adventists to attain a high standard of living in } \\
\text { the Adventist church. It is also supposed to have a second impact in the world in order to } \\
\text { lessen the suffering in the world." }\end{array}$ \\
\hline 3 & Influence & $\begin{array}{l}\text { "The Bible is actually telling us, the spirit of prophecy is clearly telling us, this is the way to } \\
\text { go. If you want to reach more people, you need to start with their physical needs. That's } \\
\text { Ellen White. The Bible tells us a lot about that too, Isaiah 58, Ministry of Healing (p. 143), } \\
\text { this is the way to go if you want to impact the world, and that's the reason why I am so } \\
\text { much convinced about the health message." }\end{array}$ \\
\hline 4 & Influence & $\begin{array}{l}\text { "Number } 1 \text { increases the number of years and at the same time increases the quality of } \\
\text { years. But, I think it's also important to realize that this program is really not only for us, but } \\
\text { God has given us so that we can serve others. That's very important, otherwise we would } \\
\text { just be self-serving." }\end{array}$ \\
\hline 9 & $\begin{array}{l}\text { Centers of } \\
\text { influence }\end{array}$ & $\begin{array}{l}\text { "Of course, we have the center of influence in the city. We put up hygienic restaurants, and } \\
\text { we have clinics where we could do healthy lifestyle consultancy, we offer it for free, and we } \\
\text { also serve foods for those who want to dine in the restaurants and we conduct health } \\
\text { lectures and we do healthy lifestyle campaign conventions where people are invited." }\end{array}$ \\
\hline
\end{tabular}

\section{Center of influence category}

The idea of centers of influence was a common notion in the responses. Table 1 highlights some of the ideas running through the interviews that informed the centers of influence category. Hence, the core category of this study was identified as centers of influence. Therefore, the finding drawn from the concept of mission and center of influence is that the establishment of centers of influence will serve as a powerful hub to create, promote and 
nurture the SDA health-lifestyle programs whose ultimate goal is to direct lives to eternal life. Arguably, this category represents the sponsoring organization's (SDA-church) strategic thrust. The strategic thrust suggested by the SDA health lifestyle programs seems to go beyond health-lifestyle and longevity to soul winning.

In SDA literature, centers of influence have been described as institutions linking the community through service, typically in urban settings. The centers are expected to be multi-dimensional facilities offering various services including healthy food outlets and treatment rooms. The centers are taking different forms around the world including, "health clinics, music centers, recreational facilities and message centers" (Krause 2014 p. 10).

The notion of centers of influence also exists in nonSDA literature. Centers of influence refer to, "people or organizations that can boost market access and credibility through referrals, testimonials, and simple undervalued word of mouth." They are usually well established networks with social and political power (Clagett 2013 p. 1). This description is from a sales and marketing perspective. It highlights that centers of influence can be institutions or individuals. The notion of centers of influence is thus premised on the institution's ability to generate referrals and positive word of mouth communication. The idea of referrals reflects the domino effect suggested by the substantive theory emerging from this study.

Descriptions of centers of influence in both SDA and non-SDA literature seem scant. Examples of other authors who mention centers of influence include Grey (1995) and Tyler (2003). Tyler (2003) further uses the term to refer to an influential person in a human resources setting. Grey (1995) discusses centers of influence in the context of sales and generating referrals suggests that referrals from centers of influence are based on trust. The limited literature available on the concept suggests that it can be developed further. This study looked at centers of influence primarily as institutions. However, individuals can also serve as centers of influence.

\section{Context-guiding Philosophy}

The data suggested that a guiding philosophy or worldview is the major context that influences centers of influence and the programs run under such centers. The idea of a biblical foundation was a common notion in the responses. Table 2 highlights examples of elements of the guiding philosophy as they were expressed by some of the respondents.

Table 2: Guiding Interview Excerpts

\begin{tabular}{|c|c|c|}
\hline Case & Concept & Interview excerpt \\
\hline 6 & $\begin{array}{l}\text { Biblical and } \\
\text { scientific }\end{array}$ & $\begin{array}{l}\text { "I always insert the biblical principles behind what I teach . . . because as Adventists we } \\
\text { follow the Bible, and once they are open to that, I introduce E.G. White and the elements } \\
\text { she taught that are now being proven by scientific evidence." }\end{array}$ \\
\hline 4 & $\begin{array}{l}\text { Quality } \\
\text { longevity }\end{array}$ & $\begin{array}{l}\text { "It's also going to add what we call quality in your years; it's not only just going to be the } \\
\text { quantity in your life, but also the quality, wherein, you actually have more years and these } \\
\text { years are relatively free of diseases. What's the point of extending your life if you are } \\
\text { actually going to be sick?" }\end{array}$ \\
\hline 6 & Preventive & $\begin{array}{l}\text { "I educate people, I teach them what are the principles of helpful living so that one can not } \\
\text { only prevent diseases. . . there is a lot of money in the church. . . . We won't pay for them } \\
\text { when they undergo a CHIP program, but we pay for them when they get a heart attack and } \\
\text { when they need an operation. So how crazy is that? Some people think that if you are ever } \\
\text { ill, then you can match it with a pill and Dr.' bill. So, pill and bill right. That's the easiest way } \\
\text { people understand the medical system, but we are changing that. So now its education as } \\
\text { medicine and of course food is number } 1 \text {. So, we teach them the principles of nutrition, and } \\
\text { we teach them how to cook and prepare food, and of course, they enjoy eating it." }\end{array}$ \\
\hline 11 & Wholistic & $\begin{array}{l}\text { "The benefit of health is spiritual, physical and mental. So, it's all the dimensions. . . . So, } \\
\text { what I value most about the programs is that they are balanced, comprehensive and doable. } \\
\text { So, if you give somebody too much, and its' like either or, then they will not follow it." }\end{array}$ \\
\hline
\end{tabular}

The participants also gave merit to the idea of a global emphasis in the SDA health-lifestyle programs. One of the academics interviewed (case
1) reflecting on her experience as a health director, raised the issue of the central planning of healthlifestyle programs at the General Conference of the 
SDA Church before they are disseminated to different world regions. She claimed that "normally as a health director, our programs were cascaded from the General Conference (GC) to the Division and finally to the Union, then only to the mission. We were practically the implementers. The GC is the global headquarters of the SDA church while the division is a regional headquarters, and the union is a local headquarters typically representing a geographical location in a country.

In this study the guiding philosophy of the SDA health-lifestyle programs was found to comprise six of dimensions- biblical foundation, scientific foundation, focus on quality longevity, focus on prevention, global scope, and holistic approach. Likewise, non-SDA sponsored programs can be guided by the developer's worldview.

\section{Guiding Philosophy}

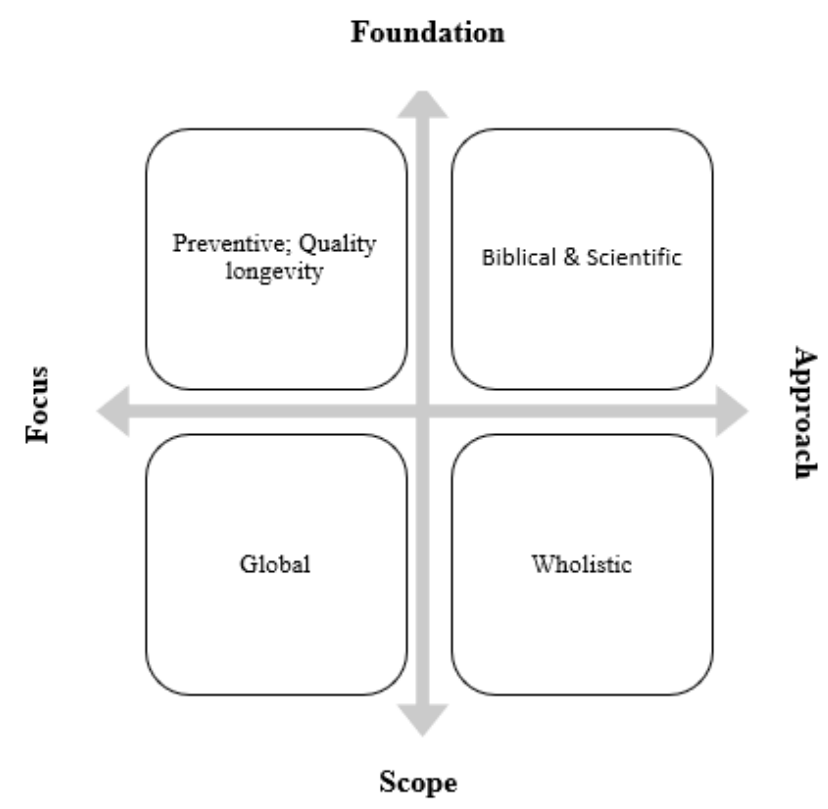

Figure 2: Summary of Guiding Philosophy Directing Centers of Influence

Arguably, if the participants in this study were not SDA members, their responses would have reflected a different worldview. It seems that the current social marketing models have not considered worldview as a component that influences the development of social marketing programs nor its importance when considering health behavior modification initiatives. For example, the model by Englert, Sommerville and Guenole (2009) focuses on the behavior change process and their corresponding communication stages as well as follow-up processes. On the other hand, Piskoti and Odel (2012) highlights the planning cycle for social marketing activities.

Pointedly, Piskoti and Odel (2012) separates institutional approaches to behavior change from problem oriented approaches. Evidently the emergent model in this study is an institutional approach to health behavior modification. We suggest that a worldview or guiding philosophy is important for such approaches particularly faith based approaches. For instance, if we use French and Russel-Bennett's (2015) hierarchal social marketing model with a core principle, concepts and techniques, our view is that the core principle in any such behavior change program is informed by the developer's world view. Similarly, the desired behavior component in the Integrative model for social marketing by Lefebvre (2011) is also a function of a worldview.

\section{Causal condition-program benchmarking}

The concept of expected benchmarks cuts across the data and is the suggested causal condition impacting the core category (centers of influence). The lessons have been divided into two: (a) Those benchmarks described as performance driversexchange, group support, professionalism, benchmarking, innovation, top leadership support, collaboration, contextualization and, those dealing with myths, and (b) Those that pertain to the 
content and structure of the programs. Table 3

expressed by respondents.

highlights some of the ideas on benchmarking

Table 3: Benchmarking Interview Excerpts

\begin{tabular}{|c|c|c|}
\hline Case & Concept & Interview excerpt \\
\hline 18 & collaborations & $\begin{array}{l}\text { "I remember working with the office of the ministry of health in my country. They } \\
\text { were quite open ... that led to encounters with universities, schools, malls, where I } \\
\text { went, and the center of this program is in this setting. The people were surprisingly } \\
\text { open to it." }\end{array}$ \\
\hline 14 & Contextualization & $\begin{array}{l}\text { "I wish the program can be designed for an Eastern mindset. I think the program, as } \\
\text { it is, is designed for a western mindset. Most of the foods on the menu were } \\
\text { western. I think the program should be naturalized, I mean Asianized, with the foods } \\
\text { that we have here. Some of the foods they prescribed were expensive and they are } \\
\text { not even on our menu here." }\end{array}$ \\
\hline 16 & Group support & $\begin{array}{l}\text { "We created friends, and we became more motivated to exercise because we had a } \\
\text { support group." }\end{array}$ \\
\hline 17 & & $\begin{array}{l}\text { "First, something I really liked was the support group. We were placed in different } \\
\text { groups and we were there to support each other, to follow up on, to encourage, ... } \\
\text { that is something that made a difference for me." }\end{array}$ \\
\hline 1 & Professionalism & $\begin{array}{l}\text { "so when the health ministry came in and the center was manned by professional } \\
\text { people, health professionals, nurses' doctors, nutritionists, and we had health } \\
\text { volunteers." }\end{array}$ \\
\hline
\end{tabular}

Program Benchmarks

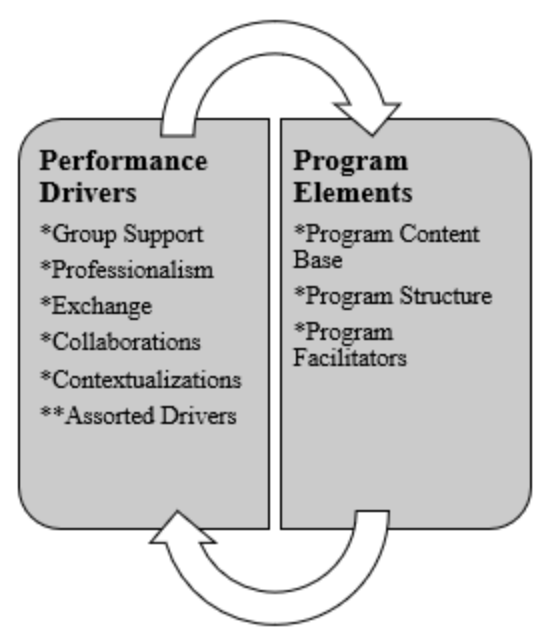

Figure 3: Summary of Program Benchmarks for Centers of Influence

The content of SDA health-lifestyle modifications seems to be centered on the 'NEWSTART' or 'CELEBRATIONS' concepts. One of the health directors (case 3) added credence to the claims when he observed that "the church has a healthy lifestyle program called CELEBRATIONS. Of course, we started as NEWSTART, but later on, the GC has developed a very comprehensive healthy lifestyle modification which we call CELEBRATIONS. C stands for choice; E stands for exercise..." Hence a key finding was that these concepts serve as benchmarks for the content of SDA health-lifestyle initiatives.
The concepts of benchmarks cutting across the data focused on different aspects of health-behavior change programs ranging from contextualization to innovation. The notion of social marketing benchmarking is prevalent in literature (see Carrete \& Arroyo 2014: Fry, Previte \& Brennan 2017; Kubacki, Rundle-Thiele, Lahtinen, \& Parkinson (2016; Wettstein \& Suggs 2016). Dinan and Sargeant (2000) as well as Ludwig, Buchholz and Clarke (2005) which explored the concept of partnerships which is closely related to benchmarking. 
Some of the benchmarks evident in this study were corroborated by others in extant studies. Those benchmarks that were corroborated in literature are highlighted in this section. First, the idea of contextualization relates to segmentation which is a key tenet of marketing. Second, the idea of exchange is explored by Rosenberg (2006) in relation to free services and in relation to monetary costs and benefits (Lefebvre 2013; Lee \& Kotler (2016). Third, the idea of group support connects with the notion of peer advocacy (Barlovic 2006; Dinan \& Sargeant 2000; Domegan 2008; Watson, Tomar Dodd, Logan \& Choi 2009) and influence others (Lee \& Kotler, 2016). Fourth, modelling is discussed in the context of social modelling and its positive effects on behavior modification (Evans 2008; Mckenzie-Mohr 2011) as well as Bandura's social learning theory as a basis for modeling (cited in Donovan 2011). Lastly training and education relate to advocacy, motivation, education (Piggford, Raciti \& Harker, 2008) and educational entertainment (Evans 2008; Ganeshasundaram \& Henley (2009). Evidently these concepts contextualization, exchange, group support, modelling, as well as training and education can be traced to other concepts in literature.

\section{Actions and Strategies}

Five strategies and actions were evident in the interview data. These pertained to program recruitment, program procedures, program incentives, program communications and program evaluations. These strategies and actions are obviously not exhaustive since the purpose of the study was not to identify strategies and action plans. Figure 5 illustrates the actions and strategies.

Table 4: Actions and strategies interview excerpts

\begin{tabular}{|c|c|c|}
\hline Case & Concept & Interview excerpt \\
\hline 2 & Recruitment & $\begin{array}{l}\text { "“They were able to recruit some people and I think that is very positive. } \\
\text { They recruited some people to come you know, 'please this program is very } \\
\text { good, ...' and all these things." }\end{array}$ \\
\hline 9 & $\begin{array}{l}\text { Implementation of } \\
\text { procedures }\end{array}$ & $\begin{array}{l}\text { "I do a free cleansing program and after they receive this cleansing } \\
\text { program, they become witnesses and also get to influence others especially } \\
\text { their families." }\end{array}$ \\
\hline 16 & Incentives & $\begin{array}{l}\text { "There was a time when we danced, there was music, this was the very first } \\
\text { time we were allowed to dance and I liked it very much..." }\end{array}$ \\
\hline 16 & Incentives & $\begin{array}{l}\text { "I still remember this slogan, eat more weigh less. You can actually eat a lot } \\
\text { and lose weight" }\end{array}$ \\
\hline 16 & communication & $\begin{array}{l}\text { "...I think the personal approach more than the video and the } \\
\text { announcement. When someone came to me personally, I valued that" }\end{array}$ \\
\hline 17 & Evaluation & $\begin{array}{l}\text { "But you can always come back to follow that and the testimonies every } \\
\text { day every meeting, we had testimonies of a transformation of life either by } \\
\text { participants or by CHIP alumni, they would share." }\end{array}$ \\
\hline
\end{tabular}

Therefore, recruitment, evaluation, implementation, incentives, and communication are the program actions/strategies that characterize Adventist health lifestyle programs.

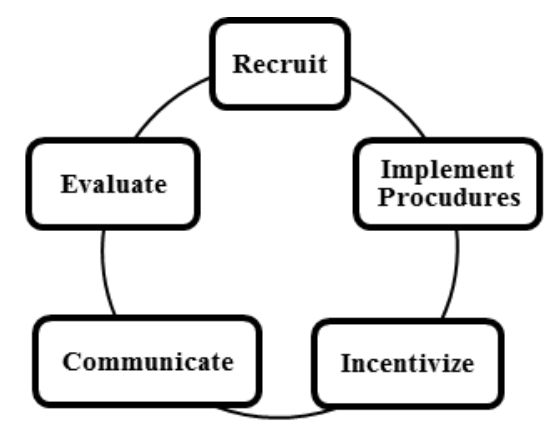

Figure 4: Strategies and Actions for Centers of Influence Recruitment, implementation, incentives, communication and evaluation (see Figure 4) highlight some program tactical and probably strategic planning elements that were evinced by the data. One of the interesting things that came out about recruitment is that the reasons cited for joining health-lifestyle programs were largely marginal. For example, some participants noted that they joined just to honor a friend who had invited them so that he could meet his target number of recruits for the program. The idea of attributing fringe reasons as the key motivation for joining programs echoes the concept of peripheral persuasion (Riechert et al. 2001; Tan, et al. 2010). Therefore such peripheral persuasions should be identified and made the focus of social marketing communication and positioning efforts.

\section{Social Marketing Design Criteria}

The social marketing design criteria highlight four major components that should be considered when 
designing social marketing programs. First, social marketing action plans; second, social marketing built environment; third, social marketing benchmarking criteria, and finally, social marketing design criteria. The four are outlined below.

Social marketing action plans: The studies reviewed referred to social marketing and sometimes commercial marketing action plans. The studies highlighted that social marketing uses commercial marketing tools to address social problems (Adascalitei et al., 2013; Carrete \& Arroyo, 2014; Dietrich et al., 2016; Gordon, 2013; Lee \&Kotler, 2016; Kubacki et al., 2015; Lynes et al., 2014; Twenewboah-Koduah \& Owusu-Frimpon, 2015). These authors suggest that the basic tenets of commercial marketing are useful in social marketing campaigns. Ostensibly, the tenets in question center on concepts such as segmentation, targeting, positioning, the marketing mix, the marketing concept, and marketing planning, among others.

Social Marketing Built-Environment: The studies raised the concept of a social marketing builtenvironment. The concept of the built environment suggests that it is easier to make behavior modifications if the environment is designed to facilitate such modifications. The hectic schedule of a demanding job; a cultural orientation that values rich, fatty foods; or ease of access to harmful products, are cited as examples of a poor built environment. In such a situation, it would be necessary to devise healthier options and make them easily accessible in order to facilitate behavior change (Carrete \& Arroyo, 2014; Dietrich et al., 2016).

Schuster et al. (2016) observe that providing noticeable prompts and ensuring that the community is exposed to good models of proper reference groups also improves the built environment. Wymer (2011) further argues that the built environment can also be improved by addressing upstream factors. He suggests that handling problems at the community level rather than at an individual level is one way of improving the built environment. In some instances, legislation or policies may be part of upstream strategies that can be used. The availability of a safe environment may make it easier for people to opt for walking instead of driving (Coulon et al., 2012); while technological innovations may make it easier to initiate age verification to prevent selling alcohol to underage kids. The environment should address the barriers for behavior modification such as cultural taboos and economic factors. Twenewboah-Koduah and Owusu-Frimpon (2015) discuss the stigmas that go with the use of contraceptives among different faith groups. All these factors make a case for the importance of the built environment in successful social marketing campaigns.

Social Marketing Benchmarking Criteria: The issue of benchmarking came up in the studies. The studies evince the notion of social marketing benchmarking criteria just like it was in the social marketing models that were outlined above. The discussion on social marketing models above highlighted how social marketers have been keen to identify criteria which qualifies or disqualifies a campaign as truly social marketing. Several studies reviewed also point to forms of social marketing benchmarking criteria. Discussions on the following social benchmarking criteria characterized the studies: community based social marketing benchmarking criteria (Lynes et al., 2014; Schuster et al., 2016), Andreasen's 2006) social marketing benchmarking criteria (Fry et al., 2017; Kubacki et al., 2015; Wettstein \& Suggs, 2016), social marketing indicator (Wettstein \& Suggs, 2016), French and Blair-Steven's national social marketing center (Fry et al., 2017; Kubacki et al., 2015), Robison-Maynard et al (2013), social marketing benchmarking criteria (Kubacki et al., 2015), Lee \&Kotler's principles of success (Lee \& Kotler, 2016), Stead et al (2007), six essential benchmarks of a social marketing campaign (Carrete \& Arroyo, 2014).

The use of theories from diverse fields was evident in the data. It is evident in the studies that social marketing programs make use of various theories from different fields when designing social marketing campaigns. The following theories were highlighted-theory of planned behavior (Adascalitei et al., 2013; Carrete \& Arroyo, 2014; Lee \& Kotler; Ma et al., 2017; Manikam \& Russell-Bennett, 2016), concepts from public health (Wymer, 2011), theory of reasoned action (Carrete \& Arroyo, 2014; Manikam \& Russell-Bennett, 2016; Wymer, 2011), social cognitive theory (Carrete \& Arroyo, 2014; Lee \& Kotler; Wymer, 2011), health belief model (Adascalitei et al., 2013; Carrete \& Arroyo, 2014; Lee \& Kotler; Wymer, 2011), hierarchy of effects theory (Fry et al., 2017), stages of change model ( Lee \& Kotler), social norms theory (Lee \&Kotler) exchange theory ( Lee \& Kotler), expected utility theory (Carrete \& Arroyo, 2014), protection motivation theory (Carrete \&Arroyo, 2014), 
personal communication network (Manikam \& Russell-Bennett, 2016), ecological systems theory (Farrell \& Gordon, 2012).

Social Marketing Design Criteria: Several concepts highlighted by the studies reviewed pertained to the design of social marketing programs. Four design elements were identified-assorted design elements, upstream design thrust, downward design thrust, and midstream design thrust. Several concepts pertaining to designing social marketing programs were outlined. The following concepts pertaining to design can be highlighted: co-designing programs with participants (Schustern \& Connor 2016), use of experts in designing programs (Schustern \& Connor 2016), focusing on multiple ecological levels (Fry et al., 2017; Adascalitei et al., 2013), multiple level communications (Carrete \& Arroyo, 2014; Lee \& Kotler, 2016; Twenewboah-Koduah \& OwusuFrimpon, 2015) and focus on desired nonvisible end state behaviors (Lynes et al., 2014).

The term downstream marketing is used in some of the studies to refer to campaigns that target final consumers. The following concepts focusing on final consumers can be highlighted: use of music (Lynes et al., 2014), educational campaigns (Schustern \& Connor 2016; Twenewboah-Koduah \& OwusuFrimpon, 2015), use of label information (Schustern \& Connor 2016; Carrete \& Arroyo, 2014), evaluation of products/services based on sensorial attributes (Schustern \& Connor 2016), capacity building (Whitelaw et al., 2011),tailor-made campaigns (Ma et al., 2017; Twenewboah-Koduah \& OwusuFrimpon, 2015).

Similarly, there was also reference to upstream marketing. Upstream marketing referred to social marketing campaigns that targeted leaders and policymakers in communities. The following concepts were identified on upstream thrust: multiple collaborations (Adascalitei et al., 2013; Carrete \& Arroyo, 2014; Whitelaw et al., 2011), leadership support (Whitelaw et al., 2011), application of Andreasen benchmarking criteria (Previte and Brennan, 2017) influencing policy makers, regulators, managers and educators (Farrell \& Gordon, 2012), ecological systems theory (Gordon, 2013) and advocacy (Allyson Dooley et al., 2012).

There were also references to midstream campaigns or those that targeted middlemen on the social marketing value chain. The following concepts were identified on midstream thrust: strengthening ties with retailers (Kamin \& Kokole, 2016) and community development approaches (Ma et al., 2017).

The finding states that the social marketing design criteria such as (a) marketing strategy, (b) builtenvironment, (c) benchmarking criteria and (d) design conditions could make the SDA health lifestyle programs more effective. It represents an emergent theme from the models and extant studies which were constructed as, 'social marketing program design criteria'. The design criteria are illustrated by Figure 5.

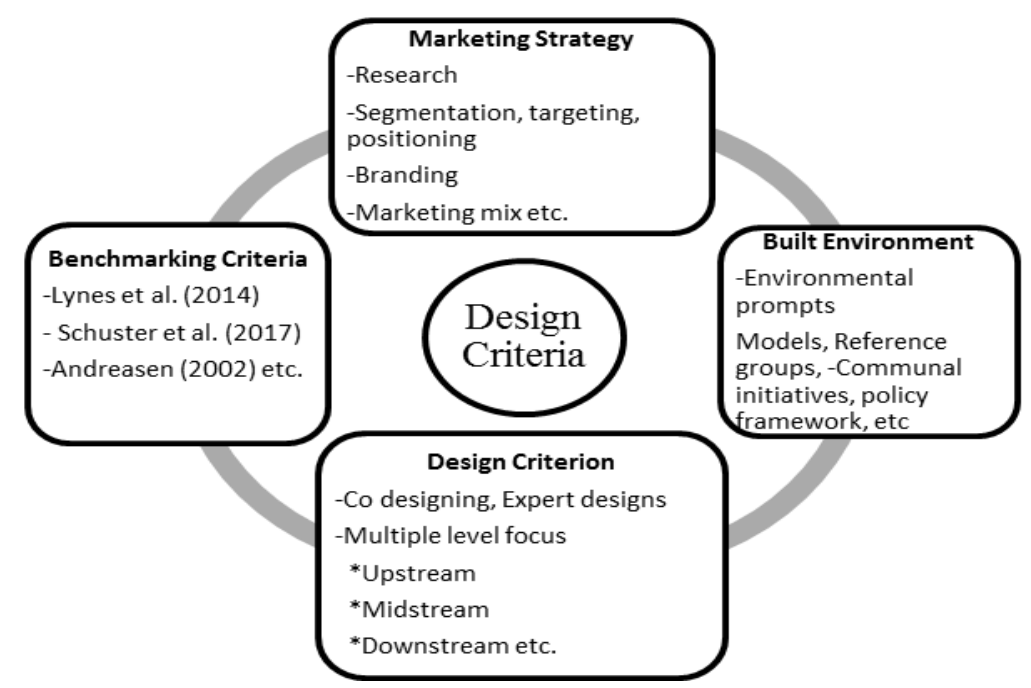

Figure 5: Social Marketing Design Criteria for Centers of Influence

\section{The metaphor of digital beacons}

The concept of a digital beacon has been adopted to illustrate the emerging theory. Figure 6 illustrates centers of influence as a digital beacon. The theory and the illustration are consistent with the sentiments expressed in the interviews that the 
main goal of the SDA health-lifestyle programs is to spread the influence of the SDA health-lifestyle. A digital beacon transmits and receives signals thereby facilitating communication. Similarly, individuals and organizations are potential centers of influence that can receive and send the SDA health-lifestyle influence.

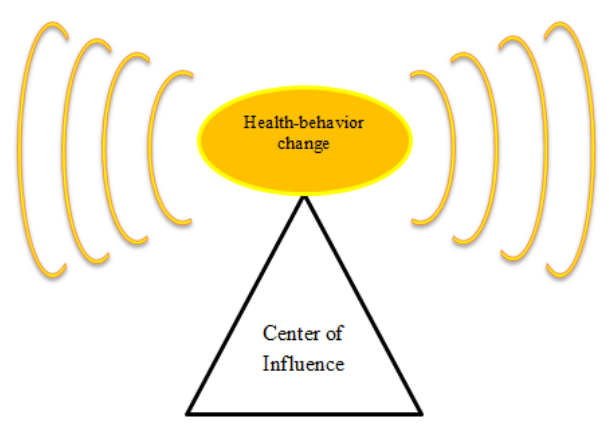

Figure 5: Social Marketing Design Criteria for Centers of Influence

\section{Conclusions and Recommendations}

Generally, the emerging theory from this study is that health behavior modification is driven by centers of influence that run benchmarked programs shaped by the distinctive SDA worldview and guided via marketing design criteria. Specific conclusions and recommendations are as follows:

Health behavior programs and initiatives can be implemented through centers of influence when they run health behavior modifications in line with identified benchmarks and social marketing design criterion guided by the SDA worldview. Accordingly, they should be established where they are not already in existence.

Health behavior programs, initiatives and institutions are guided by the worldviews of those who initiate and develop them. So, developers of health behavior programs, initiatives and institutions can develop well thought out worldview statements so as to provide unified direction and perspective.

The implementation of identified benchmarks-group support, professionalism, exchange, collaborations, contextualization, innovation, top leadership support, benchmarking, simple solutions and dealing with myths is expected to improve healthbehavior modification initiatives. Additionally the content of health behavior modifications is expected to be rooted on the NEWSTART or CELEBRATIONS concepts. NEWSTART is the acronym for (N)-nutrition, (E)-exercise, (W)-water,
(S)-sunlight, (T)-temperance, (A)-air, (R)=rest, (T)trust in God while CELEBRATIONS is the acronym for (C) choices, (E) exercise, (L) liquid, (E) environment, (B) belief, (R) rest, (A) air, (T) temperance, (I) integrity, (O) optimism, (N) nutrition, and (S) social support and services." Hence, the benchmarks identified should be implemented as a way of enhancing the healthbehavior changes.

The action plans highlighted in the study-recruit, implement procedures, incentivize, communicate and evaluate point to the broader concept of planning at both strategic and tactical levels which is necessary for health behavior modification initiatives to succeed. Specific concepts such as peripheral persuasion can be useful in areas such as recruitment as well as marketing communications. So, a complete and comprehensive set of strategies and action plans should be devised to ensure that clear standard operating procedures are available.

These social marketing design criteria- marketing action plans, built environment, benchmarking and design measures fulfil the social marketing criterion of health behavior modification initiatives. Social marketing design criteria should therefore be incorporated in behavior modification initiatives. Specifically, those interested in achieving health behavior modification should: (1) devise appropriate marketing action plans covering segmentation, targeting, positioning, branding and the marketing mix for each center of influence or health behavior modification initiatives, (2) develop an appropriate built environment to make it easier to attain the desired change. That may include lobbying policy makers and even legislators so that appropriate prompts are availed and initiatives are made at group and community levels, (3) adopting appropriate social marketing benchmarking criteria such as the (NSMC 2014), (a) seek to change specific behaviors rather than just attitudes and knowledge, (b) study your target audience, (c) use behavioral theories to understand and inform interventions, (d) identify specific actionable insights to focus the interventions, (e) minimize the costs and maximize the benefits of the desired behavior, ( $f$ ) seek to understand competitive behaviors, (g) tailor interventions for specific segments and avoid a one size fits all, (h) use a variety of methods to elicit the behavior change, (i) ensure multiple level focus (upstream, midstream, downstream) for the centers of influence and the health behavior programs they run. 
Examples of upstream initiatives that can be considered include-lobbying leaders and policy makers

Devising collaborations, and setting ecological systems. Examples of midstream initiatives that can be considered include-devising community development initiatives. Examples of downstream initiatives that can be considered include-using music, capacity building and appealing to sensorial attributes for evaluation programs.

\section{Reference}

Adascalitei, V., Musetescu, A., \& Fruth, A. (2013). The European Union a remarkable framework for social marketing implementation. Knowledge Horizons, 5, 914.

Andreasen, A. R. (2006). Social marketing in the 21st century. London: SAGE.

Allyson Dooley, J., C. Jones, S., \& Iverson, D. (2012). Web 2.0: an assessment of social marketing principles. Journal of Social Marketing, 2, 207-221.

Barlovic, I. (2006). Obesity, advertising to kids, and social marketing. Young Consumers, 7, 2634.

Buettner, D. (2010). The blue zones: Lessons for living longer from the people who've lived the longest. Washington, D.C., Enfield: National Geographic Society; Publishers Group UK.

Bryman, A., \& Bell, E. (2007). Business research methods (3rd ed.). Oxford, UK: Oxford University Press.

Carrete, L., \& Arroyo, P. (2014). Social marketing to improve healthy dietary decisions-Insights from a qualitative study in Mexico. Qualitative Market Research: an International Journal, 17, 239-263.

Charmaz, K. (2014). Constructing grounded theory (2nd edition). Introducing qualitative methods. Los Angeles: SAGE.

Clagett, B. (2013). Who are your centers of influence? Retrieved from https://www .cuinsight.com/who-are-your-centers-ofinfluence.html, updated on 12/18/2018, checked on 12/18/2018.

Cooperrider, D. L., Whitnye, D., \& Stavros, J. M. (2008). Appreciative inquiry handbook: For leaders of change. Brunswick, $\mathrm{OH}$ : Crown Custom Publishing.

Corbin, J., \& Strauss, A. (2015). Basics of qualitative research techniques and procedures for developing grounded theory (4th ed.). Los Angeles, CACalifornia: SAGE.

Coulon, S. M., Wilson, D. K., Griffin, S., St George, S. M., Alia, K. A., Trumpeter, N. N., .. Gadson, B. (2012). Formative process evaluation for implementing a social marketing intervention to increase walking among African Americans in the Positive Action for Today's Health trial. American Journal of Public Health, 102, 2315-2321.

Dietrich, T., Rundle-Thiele, S., Schuster, L., \& Connor, J. (2016). Co-designing social marketing programs. Journal of Social Marketing, 6, 41-61.

Dinan, p. S. C., \& Sargeant, L. M. A. (2000). Social marketing and sustainable tourism? Is there a match? International Journal of Tourism Research, 2, 1-14.

Domegan, C. T. (2008). Social marketing: implications for contemporary marketing practices classification scheme. Journal of Business \& Industrial Marketing, 23, 135141.

Donovan, R. (2011). Theoretical models of behavior change. In G. Hastings, K. Angus, \& C. Bryant (Eds.), The SAGE Handbook of Social Marketing (pp. 14-32). London, UK: SAGE.

Englert, P., Sommerville, S., \& Guenole, N. (2009). Application of the social marketing model to unemployment counseling: A Theoretical Perspective. Journal of Employment Counseling, 46(3), 107-114.

Evans, W. D. (2008). Social marketing campaigns and children's media use. The Future of Children, 18, 181-203. https://doi.org /10.13 53/foc.0.0009.

Farrell, T., \& Gordon, R. (2012). Critical social marketing: Investigating alcohol marketing in the developing world. Journal of Social Marketing, 2, 138-156.

French, J., \& Russell-Bennett, R. (2015). A hierarchical model of social marketing. Journal of Social Marketing, 5(2), 139-159. 
Fry, M.-L., Previte, J., \& Brennan, L. (2017). Social change design: disrupting the benchmark template. Journal of Social Marketing, 7, 119-134.

Galvez, C. A. (2016): A wholeness approach for the Adventist health message. In International Forum 19 (2), pp. 114-132.

Grey, S. E. (1995). Center of influence. Key to a successful marketing plan. Life Association News, 90(8).

Ganeshasundaram, R., \& Henley, N. (2009). Reality television (Supernanny). A social marketing "place" strategy. Journal of Consumer Marketing, 26, 311-319.

Glaser, B. G., \& Strauss, A. L. (1967). The Discovery of grounded theory: Strategies for qualitative research. Observations (Vol. 1).

Gordon, R. (2013). Unlocking the potential of upstream social marketing. European Journal of Marketing, 47, 1525-1547.

Hung, C.-L. (2017). A meta-analysis of the evaluations of social marketing interventions addressing smoking, alcohol drinking, physical activity, and eating. Indiana Graduate School.

Hunter, A; Brewer, J (2015): Designing Multimethod Research. In Sharlene Hesse-Biber, R. Burke Johnson (Eds.): The Oxford handbook of multimethod and mixed method research inquiry. New York: Oxford University Press, pp. 185-205

Kamin, T., \& Kokole, D. (2016). Midstream social marketing intervention to influence retailers' compliance with the minimum legal drinking age law. Journal of Social Marketing, 6, 104-120.

Kemp, G., \& Eagle, L. (2008). Shared meanings or missed opportunities? The implications of functional health literacy for social marketing interventions. International Review on Public and Nonprofit Marketing, 5(2), 117-128. http://doi.org/10.1 007/s12208-008-0012-7.

Kotler, P. (1999). Kotler on marketing: How to win, and dominate markets. London: Butler and Tanner.

Krause, G. (2014). Seeking the Shalom: Wholistic Adventist urban mission and centers of influence. Journal of Adventist Mission Studies, 10, 49-61.

Kubacki, K., Rundle-Thiele, S., Lahtinen, V., \& Parkinson, J. (2015). A systematic review assessing the extent of social marketing principle use in interventions targeting children (2000-2014). Young Consumers, 16, 141-158.

Lee, N. R., \& Kotler, P. (2016). Social marketing: Changing behaviors for good (5th edition / Nancy R. Lee, Philip Kotler). Los Angeles: SAGE.

Lefebvre, R. C. (2011). An integrative model for social marketing. Journal of Social Marketing, 1(1), 54-72.

Lefebvre, R. C. (2013). Social marketing and social change: Strategies and tools for health, wellbeing, and the environment / R. Craig Lefebvre. San Francisco, CA.: Jossey-Bass.

Longest, B. B. J., \& Rohrer, W. M. (2005). Communication between public health agencies and their external stakeholders. Journal of Health Services Administration, 28(1/2), 189.

Ludwig, T. D., Buchholz, C., \& Clarke, S. W. (2005). Using social marketing to increase the use of helmets among bicyclists. Journal of American College Health, 54, 51-58.

Lynes, J., Whitney, S., \& Murray, D. (2014). Developing benchmark criteria for assessing community-based social marketing programs. Journal of Social Marketing, 4, 111-132.

Ma, L., Mulley, C., \& Liu, W. (2017). Social marketing and the built environment: What matters for travel behaviour change? Transportation, 44, 1147-1167.

Manikam, S., \& Russell-Bennett, R. (2016). The social marketing theory-based (SMT) approach for designing interventions. Journal of Social Marketing, 6, 18-40.

NSMC (2014). Social Marketing Benchmarking Criteria. available at: https://www.cul turehive.co.uk/resources/social-marketingbenchmark- criteria//default /files/be nchmark-criteria-090910.pd. (Accessed 11 April 2021)

McKenzie-Mohr, D. (2011). Fostering sustainable behaviour: An introduction to community- 
based social marketing (3rd ed.). Philadelphia, PA: New Society.

Piggford, T., Raciti, M., Harker, D., \& Harker, M. (2008). Young adults' food motives: An Australian social marketing perspective. Young Consumers, 9(1), 17-28.

Piskóti, I., Ph, D., \& Odel, I. N. M. (2012). The social problem sensitivity of the Hungarian population and Their Social Marketing Sensitivity, Club of Economics in Miskolc' TMP Vol. 8., Nr. 1, 8(1), 59-67.

Robison-Maynard, A., p. (2013). What are the key criteria that act as the predictors of success in a social marketing campaign? (Doctoral dissertation). University of Huddersfield, UK.

Rosenberg, J. (2006). Social marketing need not fail after donors withdraw. International Family Planning Perspectives, 32(1), 5.

Schuster, L., Kubacki, K., \& Rundle-Thiele, S. (2016). Community-based social marketing: effects on social norms. Journal of Social Marketing, 6, 193-210.

Schoonenboom, J, \& Johnson, R. B (2017): How to Construct a Mixed Methods Research Design. In Kolner Zeitschrift fur Soziologie und Sozialpsychologie 69 (Suppl 2), pp. 107-131.

Stead, M., Gordon, R., Angus, K., \& McDermott, L. (2007). A systematic review of social marketing effectiveness. Health Education, 107. doi:10.1108/09654280710731548.

Swartz, Ethné; Amatucci, Frances M.; \& Coleman, Susan (2016): Using a multiple method and mixed mode approach to examine women entrepreneur negotiating styles. In Int Jrnl of Gen and Ent 8 (1), pp. 48-68.

Sweat, M. D., Denison, J., Kennedy, C., Tedrow, V., \& O'Reilly, K. (2012). Effects of condom social marketing on condom use in developing countries: a systematic review and metaanalysis, 1990-2010. Bulletin of the World Health Organization, 90(8), 613-622A.

Tan, E. J., Tanner, E. K., Seeman, T. E., Xue, Q.-L., Rebok, G. W., Frick, K. D., ... Fried, L. P. (2010). Marketing public health through older adult volunteering: Experience Corps as a social marketing intervention. American Journal of Public Health, 100, 727-734.

Tyler, L. J. (2003). Are you a center of influence? Healthcare Financial Management, 57(3).

Twenewboah-Koduah, E. Y., \& Owusu-Frimpon, N. (2015). Social marketing communications on AIDS: Views of implementors in Ghana. Journal of Business Diversity, 15, 91-101.

Urquhart, C. (2013). Grounded theory for qualitative research: A practical guide. Los Angeles Calif., London: SAGE.

Watson, J. M., Tomar, S. L., Dodd, V., Logan, H. L., \& Choi, Y. (2009). Effectiveness of a social marketing media campaign to reduce oral cancer racial disparities. Journal of the National Medical Association, 101, 774-782.

Wettstein, D., \& Suggs, L. S. (2016). Is it social marketing? The benchmarks meet the social marketing indicator. Journal of Social Marketing, 6, 2-17.

Whitelaw, S., Smart, E., Kopela, J., Gibson, T., \& King, V. (2011). Developing social marketing capacity to address health issues. Health Education, 111, 319-331.

Wymer, W. (2011). Developing more effective social marketing strategies. Journal of Social Marketing, 1, 17-31.

Zikmund, W., Babin, B., Carr, J., \& Griffin, M. (2013). Business research methods. Australia: Cenga. 